\title{
The university of the future
}

\section{The traditional model of the US research university - based on the pre-eminence of the single-discipline department - needs to be stretched and challenged.}

$\uparrow$ he American research university is a remarkable institution, long a source of admiration and wonder. The idyllic, wooded campuses, the diversity and energy of the student populations, and, most of all, the sheer volume of public and private resources available to run them, have made them the envy of the world.

Seen from the inside, however, everything is not quite so rosy. Setting aside the habitual complexity of medical schools, which have separate healthcare and finance issues, the structure of these institutions is straightforward and consistent. The bedrock of each university is a system of discipline-specific departments. The strength of these departments determines the success and prestige of the institution as a whole.

This structure raises a few obvious questions. One is the relevance of the department-based structure to the way scientific research is done. Many argue that in a host of areas - ranging from computational biology and materials science to pharmacology and climate science - much of the most important research is now interdisciplinary in nature. And there is a sense that, notwithstanding years of efforts to adapt to this change by encouraging interdisciplinary collaboration, the department-based structure of the university is essentially at odds with such collaboration.

A second set of issues surrounds the almost static nature of the departmental system. In a country where most things are highly fluid, the fields covered by departments, as well as the pecking order between them, have remained largely unchanged for many years. As people and money have flowed, particularly over the past twenty years, to the south and the southwest, the strongest US universities and departments remain embedded in the northeast and in California. League tables drawn up by the National Academy of Sciences and others show little movement in this pecking order, even over several decades.

\section{Taking the first step}

China will join efforts to cut carbon emissions, but should not be expected to lead them.

W ith a new coal-fired plant coming online about once a week, China is on course to overtake the United States as the world's leading carbon dioxide emitter this year or next, an official at the International Energy Agency said last week (see page 954).

This means, of course, that unless China and other major nations such as India and Brazil join a global effort to mitigate the effects of climate change, tough targets and sophisticated carbon markets across the developed world will eventually pale into insignificance.
Another, perhaps more contentious, issue concerns the relevance of the modern research university to the community it serves. The established model, whatever else its strengths and weaknesses, reflects the desire of the middle classes for undergraduate training that prepares their offspring for a stable career. But how does it serve a society in which people may have to retrain and recreate their careers throughout their adult lives?

These questions are being asked throughout American academia, but nowhere more searchingly than at Arizona State University (ASU), a huge public university that is expanding to meet the needs of the United States' fastest-growing major city (see page 968). Michael Crow, its president, is executing an ambitious plan to replace the traditional model with one in which both influence and research excellence are concentrated not in departments, but in large, broadly based interdisciplinary centres with clear commercial or societal goals.

Whatever its outcome, this experiment will not of itself uproot the traditional university system. Incremental
"There is a sense that the departmentbased structure of universities is essentially at odds with collaboration." change, notably the establishment of stronger multidisciplinary entities such as Bio-X at Stanford University in California, and several new centres at Harvard, may have a greater bearing on the overall development of the system.

But ASU's effort already tells us plenty about the likely direction of the research university in the up-and-coming regions of America. The university of the future will be inclusive of broad swaths of the population, actively engaged in issues that concern them, relatively open to commercial influence, and fundamentally interdisciplinary in its approach to both teaching and research.

But the onus is still on the developed nations, who created the problem, to lead that effort.

China is now working on a national plan that will lay out the measures it intends to take to deal with climate change. Despite all the new power stations and the usual difficulty in discerning China's real intentions, there is one good reason to accept that its efforts are sincere: it is in China's self-interest to confront the problem. Assessments by both China and the Intergovernmental Panel on Climate Change have made clear that the nation is likely to be hit hard by climate change, which will increase pressure on water supplies and cut agricultural yields.

In the United States, momentum for domestic action on carbon emissions is growing. As it does so, the issue of how to ensure that China and other developing countries are on board - the issue that prevented the US Senate from ratifying the Kyoto Protocol in the 